\title{
ENTRE LA AUTORÍA Y LA REDENCIÓN: ABORDAJES CRÍTICOS ACERCA DE NIKOS KAZANTZAKIS
}

\author{
CAROLINA DÔNEGA BERNARDES. \\ Universidad Estadual Paulista. Brasil.
}

Resumen: Este artículo pretende reflexionar sobre las razones que llevan la crítica canónica de Nikos Kazantzakis a preocuparse mucho más por desentrañar la personalidad del autor, y menos por su propia obra, a la cual se dirige, a menudo, como objeto de elucidación del proyecto estético y filosófico del autor. Nos proponemos demostrar, además, que el tratamiento sobre Kazantzakis y su trabajo no es sólo debido a la posición de la crítica, sino más bien muestra una tendencia alentada por el autor, que encuentra en la literatura la acción meta-política para su redención personal, así como para trabajar en pro de la salvación colectiva en tiempos de crisis.

Palabras clave: Autoría, redención, meta-política, Nikos Kazantzakis.

\section{BETWEEN THE AUTHORSHIP AND REDEMPTION: Critical approaches about Nikos Kazantzakis}

Abstract: This article aims to reflect on the reasons that lead canonical criticism of Nikos Kazantzakis to worry a lot more about unraveling the author's personality and less about his own work, to which it addresses, often as an object for elucidating the aesthetic and philosophical project of the author. We propose to demonstrate further that the treatment to Kazantzakis and his work is not only due to the position of criticism, but rather shows a trend encouraged by the author, who finds in literature the meta-political action for personal redemption, and to work towards collective salvation in times of crisis.

Key words: Authorship, redemption, meta-political, Nikos Kazantzakis.

Recibido: 14.01 .15 - Aceptado: 27.01 .16

Correspondencia: Carolina Dônega Bernardes.
Email: biabeca@gmail.com
Magíster en estudios literarios. Doctora (c) en Teoría de la Literatura
en Universidad Estadual Paulista (UNESP-Brasil).
Dirección postal: Alameda Josephina B. Grotto, 145 - Parque dos Lagos CEP.
Ribeirao Preto. Sao Paulo. Brasil.


Toda mi alma es un grito y toda mi obra la interpretación sobre ese grito 1 . (Kazantzakis. Carta al Greco)

Tnquietud es la palabra de orden para el recorrido que ahora iniciamos. Un recorrido que no solo acompaña el nuevo periplo de Odiseo en su sed por el "más allá", sino que comienza por tratar de desvelar el móvil del itinerario incesante del escritor griego Nikos Kazantzakis (1883-1957) y el fermento filosófico que lo intensificó y direccionó.

Hombre de contradicciones, ateo, comunista, disidente, desterrado, desinteresado de los problemas sociales: así Kazantzakis era conocido en la Grecia de su época ${ }^{2}$. Hombre de aspecto sereno, resplandeciendo confianza y armonía: así era visto por los amigos. Hombre de conflictos, cretense, profeta, combatiente incansable, que jamás aceptó o reposó de una conquista: así el mismo se reconocía. Para los críticos, Kazantzakis es visto, ahora, como un hombre apasionado, filósofo, un héroe a los moldes de Odiseo, no obstante, torturado por las inquietudes. La diversidad de adjetivos para expresar el genio del autor sobretodo demuestra una personalidad que ha suscitado polémicas, reacciones extremas de admiración o repulsión, confundidas todas ellas con su trabajo literario.

La verdad, más importante que constatar el conflicto permanente en las valoraciones del autor realizadas por diferentes grupos, es percibir (y discutir) que el autor ha sido analizado por la gran crítica y por los lectores comunes como entidad real y como prueba de la filosofía subyacente en la obra. No es una tendencia aislada, pero las atenciones de todos los investigadores se vuelven al sinnúmero de $\operatorname{cartas}^{3}$ que revelan el hombre e iluminan aspectos

1 N. del T.: Para la traducción de esta frase seguí a Delfín Leocadio Garasa, sin embargo, al percatarme de variaciones respecto a la versión portuguesa en las traducciones oficiales en español, opté por traducir directamente desde ese idioma el resto de las citas, buscando transmitir y ser fiel al espíritu de la distinguida autora de este texto.

2 Peter Bien (2007, p.4) explica que hasta nuestros días actuales Kazantzakis es considerado por los jóvenes politizados griegos un egotista, devoto a la propia salvación y, por tanto, irrelevante para la realidad griega. Es importante resaltar, no obstante, que Bien procurará desmitificar esta visión simplista e inapropiada.

3 Gran parte de las cartas fue publicada por Heleni Kazantzakis en Kazantzaki. El disidente. (1974). Se trata de una reunión de cartas comentada por la autora, que se 
del proceso creativo que resultó en la producción literaria, de sus creencias filosóficas, de su búsqueda angustiada por la ascensión y por la libertad, de su identificación con personalidades de la historia humana. Algunos fueron amigos próximos, como P. Prevelakis, Kimon Friar y Heleni Kazantzakis (la esposa), y claramente trazan un perfil psicológico del autor refrendado por las cartas, otros se muestran más interesados en las experiencias personales del escritor, más en su trayectoria real que la lectura crítica de su obra. Roberto Quiroz reitera la tendencia crítica:

Una manera de continuar la búsqueda relacionada con el espíritu creador de Kazantzakis, más allá de la creación literaria propiamente tal, es la de dar espacio a los escritos personales que se refieren más al hombre. Sin embargo, hay que destacar que un librepensador como fue Kazantzakis, no deja de serlo porque cambie del plano de la literatura al del estrecho círculo de cartas escritas a sus contemporáneos. Más bien se aprecia una continuidad de fondo, una espontaneidad para proyectar sus mismas preocupaciones y tentativas intelectuales. En las cartas y otros escritos apreciamos sus imponderables anhelos y pasiones de lucha, alrededor de cuya antorcha también se iluminan pensamientos y luces de una compleja cosmovisión ligada a su vida y obra. (PIZARRO, 2003, p. 335).

Esa tendencia en proceso alerta hacia un problema en la valoración de la producción kazantzakiana: la obra sería solo un vehículo para llegar al autor, una confirmación de proyecto inicial reiteradamente divulgado. Por más que esta misma crítica afirme la grandiosidad de los textos de Kazantzakis, la jerarquía autor/obra se mantiene evidente, porque las atenciones al texto son meramente descriptivas y se esmeran en un conjunto de adjetivos valorativos que nada hacen más allá de elogiar la capacidad creativa de aquel que lo produjo, valores ésos que justifican y alimentan la imagen de autor heroico, profético e inquieto. Las palabras de Bidal-Baudier son una pequeña muestra de un discurso que se repite no solo en Cómo el hombre se hace inmortal, sino

propone elucidar la personalidad del autor y su trayectoria literaria. En el prólogo, Heleni explica que la obra atiende a un pedido de Kazantzakis, para quien la esposa sería la única en conocerlo bien, al contrario de todos los críticos que dirán solo cosas inexactas. 
también en el discurso de la crítica canónica de Kazantzakis"

Para comprender lo que vuelve tan excepcional la personalidad de Kazantzakis, mencionemos la gracia otro don que los dioses reservan a sus elegidos: una imaginación de visionario. Ésta llama la atención, desde su infancia, por su poder de transfiguración de lo real: el joven Nikos vive en plena leyenda, se desplaza en medio de ella y la recrea a cada instante; ve sirenas; intenta arrojarse al fondo de un aljibe para encontrar la ciudad encantada; (...) Dirán que es privilegio de la infancia vivir en un mundo imaginario. Dirán también que los recuerdos de infancia evocados por Kazantzakis hacia el fin de su vida en la Carta al Greco son recuerdos reconstituidos por el viejo escritor a través de los leitmotiv que fueron la obsesión de toda su existencia. No lo creo. El poeta que compuso la más grande epopeya de los tiempos modernos y que fue dueño de una potencia de visión poética que difícilmente se podía consignar y encerrar en palabras, tuvo desde la infancia, no lo dudemos, el poder ver la realidad grande, más esplendorosa, más conforme a sus deseos secretos. Esta primera visión del mundo -tan poderosa-, siguió siendo inalterable para él y es con idéntica pasión, nos dice, la misma que tenía de niño, que ha contemplado toda su vida el cielo estrellado o el mar.

La búsqueda por la aprehensión de la personalidad del autor, que habría sido constituida y reforzada por una dádiva divina, revela una crítica todavía unida a los ideales románticos. La crítica estaría en busca, por tanto, del autor inspirado, genio poseído y capaz de sentir: "fuerzas inconscientes [que] se combinan a fuerzas conscientes en la producción de la obra de arte" (MACHADO, 2006, p. 92), como aquel que tiene acceso a una revelación, a

$4 N$. del T.: Para la traducción de la frase que se presenta a continuación, seguí a Patricio Canto. Sin embargo, nos hemos permitido mantener la revitalización de la palabra 'dirão' por asuntos de redacción y que Patricio Canto traduce como 'dirá'. También, mantuvimos la traducción de la palabra 'aljibe' y que en portugués se tradujo como 'poço'.

5 Las expresiones marcadas en cursiva son nuestras para enfatizar el desarrollo de nuestro argumento. 
una verdad reservada solo a los elegidos, aquellos que tienen cierta capacidad de decodificar en forma de arte la realidad sensible. En cuanto el ideal de genio se vuelve ampliamente difundido en el Romanticismo y "pasa a ser la capacidad sintética que universaliza y transubstancia, el arte se convierte en el modelo de actividad espiritual, compartiendo, en su esencia, del carácter superior, profundo e íntimo de la realidad eterna y absoluta, de que es la única vía de acceso" (NUNES, 1993, p. 61-62). Solamente la biografía y el estudio atento de las confidencias del autor son capaces de captar el poder visionario y profético que la obra parece contener.

Kazantzakis se vuelve una entidad siempre presente en su obra, virtualmente activo como personaje y creador de sí mismo. Eso significa que, por la crítica del genio inspirado, la trayectoria de sus personajes representaría nada más que el camino hacia la trascendencia, hacia la unidad anhelada con las fuerzas visibles y las latentes del universo.

Aunque, la existencia de tal crítica todavía en la contemporaneidad puede ser valorada en sus implicaciones y en las razones que posiblemente lo incentivaran en este rumbo. La primera de ellas se relaciona con el propio Kazantzakis, el mayor fomentador de fascinación por su figura. Al confundir sus acciones con las de sus personajes, en un proceso de auto-identificación con la ficción, Kazantzakis proyecta en sus personajes el recorrido de ascensión que desearía lograr. Así como imprimió a la literatura las líneas de pensamiento que componen la trayectoria de cada una de las figuras representadas, el propio poeta procuró vivenciarlas en la práctica, atrayendo la atención para sí como una figura envuelta por la misma aura heroica que define a sus personajes. En Carta al Greco (publicación póstuma), el autor relata los pasos decisivos de su trayectoria, desde la infancia, novelando algunos pasajes, como el mismo declara. Así, más allá de la vasta producción epistolar, el autor deja al público una novela en la cual el asume el papel de héroe, de aquel que vive en el plano real las experiencias de Odiseo. En el prólogo, Kazantzakis confidencia:

Los grados decisivos para mi ascensión fueron cuatro. Y cada uno porta un nombre sagrado: Cristo, Buda, Lenin, Ulises. Esta jornada de sangre, de una de estas grandes almas a la próxima, es por lo que lucharé en especificar en este itinerario, ahora que el sol comienza a descender. La jornada de un hombre con el corazón en la boca, escalando a la áspera e incómoda 
montaña de su destino. Toda mi alma es un grito y toda mi obra la interpretación sobre ese grito. (KAZANTZAKIS, s/d, p.11).

La escritura personal de Kazantzakis revela el ansia de alcanzar, por medio de la literatura, la concretización de las teorías que envuelven hombres históricos o ficticios que abrirán camino para la fundación de una nueva forma de valoración del mundo y que lograrán subyugar el ego y la materia para recorrer un camino de abnegación, lucha y amor en favor de la colectividad, guías de la humanidad que, de algún modo, entregaron a los hombres una quimera, una utopía o una nueva religión. La correspondencia y los relatos en primera persona confidenciados en Carta al Greco $^{6}$ reflejan la búsqueda incansable de seguir los pasos de grandes guías del espíritu humano, como Jesús, Cristo, Buda y Lenin, una caminata de elevación que se cumple en el plano de la escritura, en oposición al propio movimiento que esos hombres representan.

La relación con personalidades del conocimiento humano (y aquí añadimos [a] Bergson, Nietzsche, Zorba, San Francisco de Asís) ${ }^{7}$ no puede ser descrita como mera influencia, más que eso, ella llega incluso a pautearse en una fuerte obsesión. Kazantzakis conjura esos "guías del espíritu”, pues en ellos

6 En la introducción a esta obra, Heleni advierte que su contenido "es una mixtura de hecho y ficción - una buena parte de verdad, un mínimo de fantasía. Algunas fechas fueron modificadas. Cuando menciona otras personas, es siempre con verdad, sin modificaciones. Exactamente lo que vio y oyó. Cuando habla de sus aventuras personales, existen algunas pequeñas modificaciones. Pero, una cosa es cierta: si hubiese sido capaz de reescribir este libro, lo habría cambiado. Exactamente cómo, no lo podemos saber. Ciertamente lo habría enriquecido, ya que a cada día se recordaba de nuevos acontecimientos que olvidará. Y, también, el habría ajustado -creo yo- a la realidad. Su vida real fue llena de significado, de vivencias dolorosas. De alegría y dolor -y para usar una única palabra, de "dignidad”. ¿Por qué habría de haber cambiado su vida? No por falta de momentos difíciles, de flaquezas, de fugas y de sufrimientos. Al contrario. Eran exactamente estos momentos que siempre servirán a Kazantzakis como nuevas gradas que le permitían ascender más alto. De ascender y alcanzar la cumbre que se ha prometido a sí mismo escalar antes de abandonar a los instrumentos de trabajo porque la noche comienza su descenso (s/d, p.9).

7 Las personalidades que Kazantzakis admiró se contienen en una cadena extensa, otras tantas pueden ser mencionadas: Moisés, Don Quijote, Alejandro Magno, El Greco, Gengis Kan, Dante, Santa Teresa, Cristóbal Colón. La gran parte de esos nombres, el autor dedicó poemas que componen la obra Tercinas (póstuma, 1960). 
identifica el modelo de vida ejemplar, que, para el autor, estaría relacionado con un tipo de heroicidad pertinente al mundo y época en que vivieron. A pesar del alejamiento temporal que comulgan entre sí y de la disparidad de las ideas que cultivaran (casi todas irreconciliables), esos modelos representaban para Kazantzakis un único y mismo camino: el esfuerzo heroico, vital y visionario de superación del destino y de los valores arraigados. No se ve simplemente una atracción y absorción de las ideas que cada uno de ellos informa, sino una fascinación por la trayectoria personal que los lleva a lo que Kazantzakis llamaba de "transubstanciación de la carne en espíritu", principio vitalista de creación en medio del mundo fenoménico y relativista.

En busca de ese principio y reconociendo en la lucha de sus guías su propio combate, Kazantzakis asimila esas ideas -de manera paradojal, ya que sus doctrinas no se pueden conciliar- y se esfuerza (y aquí comienza su propio combate) por armonizarlas. Es con este objetivo que revive, profundamente inmerso, la trayectoria de los guías mayores (Bergson, Cristo, Nietzsche, Buda, Lenin), cada uno a su tiempo y por etapas sucesivas, como el mismo describe en su autobiografía. Verificamos, por tanto, en esta fijación por la vida de personalidades importantes y reconocidas la obsesión que habrá engendrado la fascinación de críticos y lectores por su propia figura; obsesión que lo llevará a intitular la mayoría de sus tragedias con el nombre propio de los personajes a quien reverencia ${ }^{9}$, así como volverá central, solar, un personaje representativo de tales ideales en sus novelas ${ }^{10}$ y en la épica de Odiseo (nos referimos a la epopeya del autor Odisea, de 1938), su magno prototipo de héroe.

La percepción de que diversos hombres fueran capaces de elevarse encima de las limitaciones de su tiempo vuelve la búsqueda de Kazantzakis más feroz e inquieta. Asociando figuras heroicas con las doctrinas que

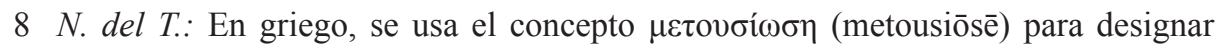
este proceso específico en Kazantzakis. Como estudioso, opté por realizar una traducción directa, porque el término en portugués transmutação (traducido como 'transmutación') puede prestarse para equívocos, si pensamos, por ejemplo, en Nietzsche.

9 Las tragedias son: Odiseo, Juliano, el apóstata, Constantino Paleólogo, Heracles, Cristóbal Colón, Cristo, Buda, Kapodistria, Teseo, Prometeo encadenado.

10 Las novelas, con sus respectivas figuras solares: Zorba, el griego (el propio homónimo, representante de la tendencia dionisíaca y vitalista), La Última Tentación de Cristo (Cristo), Cristo nuevamente crucificado (Cristo). 
sustentaran, el autor se empeña en un proyecto de ascensión que incluye vida y obra, revelando interés no por la realización estética en sí, sino principalmente por la transformación personal y colectiva. Al fundir la instancia literaria con la experiencia humana, el proyecto de "transubstanciación de la materia en espíritu” va más allá de la ficción y abarca las relaciones del autor-hombre con Dios, con el otro, consigo mismo y con la naturaleza. De este modo, nos parece evidente que Kazantzakis no distingue la trayectoria de sus héroes de la suya propia, autorizando y legitimando, por tanto, la crítica de la autoría intencional. Sería admisible, en una crítica biográfica corroborada por el autor, la inclusión de las confidencias de Kazantzakis en el conjunto de la obra literaria, pues llegaríamos aquí a las indagaciones de Foucault sobre la noción de obra: "¿Cómo definir una obra entre los millones de vestigios dejados por alguien después de la muerte?” (FOUCAULT, 1992, p.38). La definición de obra se presenta tan problemática como la definición de autor, querella histórica en el ámbito de la teoría literaria.

Al contrario de alimentarnos el debate en busca de una definición, $\mathrm{y}$ principalmente asumir una posición $\mathrm{u}$ otra en relación a la crítica de Kazantzakis, consideramos importante reevaluar determinadas conclusiones y los conflictos provenientes de las lecturas que no prevén la significación de la máxima amplitud del texto, compuesto por una diversidad de fondo: la historia, la filosofía, la biografía, el proyecto estético elaborado por el autor y la significación que se le da por la lectura. Tal amplitud característica del texto literario nos lleva a considerar la importancia de la lectura de todo material que pueda ofrecer recursos y suscitar reflexiones que permitan la apertura de los análisis, incorporando los elementos de significación no previstos por el autor y las tensiones instauradas por la obra no considerada por la crítica.

El problema, por tanto, no está en considerar las cartas y confidencias de Kazantzakis como textos válidos en la interpretación, sino el aprovechamiento que se hace de ellas, fortaleciendo una tendencia que, se quedaba solamente en la aprehensión de Kazantzakis como héroe de su propio destino, no sería un acto comprometedor en sí, sino, mucho más de lo que hizo, es un movimiento que lleva al descriptivismo del texto literario, análisis que trae como consecuencias la reproducción de pasajes considerados capitales para la confirmación del proyecto estético del autor y la asociación de personajes a sus experiencias filosóficas, bien como la síntesis del argumento y la reiteración de la complejidad poética y narrativa, finalizando que los puntos más obscuros del 
texto son misterios insolubles (probablemente porque son lagunas a las cuales Kazantzakis no dejó comentario o porque exceden su proyecto estético), como si hubiese un mensaje cifrado y solamente el conocimiento de la intencionalidad y la experiencia vivida pudiesen decodificarla y justificar su presencia en el texto.

La segunda razón que tal vez haya incentivado a la crítica a desarrollar valoraciones confirmadas por el biografismo comienza a partir de esas reflexiones, a pronunciarse. No se trata más de la legitimación ofrecida por el autor, sino de relación de la crítica con sus objetivos y procedimiento de análisis, y principalmente la subordinación a una construcción de orden psicológica: el maestro como salvador. Kazantzakis no es solamente la autoridad del texto, sino el hombre hecho maestro, reverenciado no por el aura de genio poético, común en el Romanticismo, sino por el camino de elevación que le rindió, a los ojos ajenos, el aura de los iluminados.

Lo que despierta la fascinación por Kazantzakis es el esfuerzo emprendido contra toda suerte de conflictos en busca de la superación de sí, de la redención y de la síntesis de las oposiciones. Es en este aspecto que se revela el carácter de combatiente incesante "para crecer, elevarse, para permitir la expansión de la parte divina de sí mismo y permitir a Dios que se libere de la materia." (BAUDIER, 1987, p.61). El combate es su porción heroica, íntimamente relacionada a la visión filosófica y vitalista que le sirvió de base. Comprendiendo doctrinas diversas, el sistema filosófico kazantzakiano estimuló a la atribución del título de pensador ${ }^{11}$ que ha sido sustentada, aunque poco haya utilizado (y absorbido) de las ideas de filósofos reconocidos y de conceptos ya sedimentados para componer su proyecto personal.

De ese modo, como poeta y pensador, Kazantzakis se presenta a los lectores como figura de superación y positividad en medio a lo que se ha denominado "crisis del siglo XX". Ansiando el nihilismo nietzscheano, la

11 El carácter de pensador queda bien marcado en la obra de Roberto Quiroz Pizarro, Nikos Kazantzakis. Dimensiones de un poeta-pensador, como manifestó ya en el título, revelando la propuesta de abordaje de la obra kazantzakiana confundida con la experiencia personal del autor. Vale, entretanto, notar que el trabajo de Pizarro es la disertación de maestría presentada para la obtención de grado de maestro en filosofía, lo que proporciona otra connotación a sus objetivos, aunque no minimice el tratamiento reverencioso y exaltador conferido a Kazantzakis. 


\section{CAROLINA DÔNEGA BERNARDES: Entre la autoría y la redención: abordajes...}

evolución creadora promulgada por Bergson y el concepto de "era transicional" proveniente de Oswald Spengler, Kazantzakis articula un proceso vitalista de permanente valoración de conceptos y doctrinas cristalizados por la tradición, señalando la posibilidad de creación de sí y del mundo y el descubrimiento de una nueva comprensión de Dios, en el contexto modernista de incredulidad y quiebre de la cultura occidental. Ese carácter de imprimir positividad a la negatividad del momento histórico es expandido hacia una postura que lo hace asumir el devenir de redención de la colectividad. En este aspecto, se revela hombre político, no en el sentido de comprometerse activamente por la transformación social, sino en el sentido de instar al lector al círculo vitalista en el cual estaba inserto por su propia redención.

Si muchos fueron los conflictos de Kazantzakis, uno de ellos se basó exactamente en la oposición entre acción y contemplación ${ }^{12}$, llevándolo a profundos cuestionamientos en cuanto a la actitud correcta en relación a su tiempo. El no implicamiento de manera activa con partidos y movimientos políticos, a pesar de su fase nacionalista y del interés sobresaliente por el comunismo, y la predisposición al aislamiento, a la reclusión ascética y a los cuestionamientos de orden religioso, autorizan a la crítica comprometida a considerar [a] Kazantzakis desinteresado de los problemas de su tiempo, más preocupado por la salvación personal. Peter Bien $(2007$, p.4) contesta a la tendencia, alertando hacia el hecho de que la crítica falla al no percibir que no hay separación entre las dos instancias, pues la salvación para Kazantzakis se encuentra en el compromiso con la colectividad, que puede ser valorado como político. Su interés se dirigía a la meta-política, ruta indirecta que, al pasar por lo social, lleva a la ascensión. Así, no era la política que le interesaba, sino las cuestiones suscitadas por ella para alcanzar algo más importante: la libertad.

Si el interés de Kazantzakis no estaba propiamente en la política, su modo de acción no se inserta en un campo de batalla o en los despachos ejecutivos; es en la literatura que acreditará haber encontrado su herramienta de lucha y el punto de equilibrio para la tensión acción/contemplación, pues, adquiriendo finalidad, la escritura trasciende lo estético para asumir el poder de transformación de lo real, sin que para eso Kazantzakis precisase abdicar de su

12 La tensión se manifiesta claramente en la obra Zorba, el griego: el protagonista (narrador-personaje), escritor e intelectual, se muestra angustiado por no tener el mismo impulso a la acción que Zorba, personaje que representa el polo opuesto. 
deseo de aislamiento y retiro ascético.

Escribir podría haber sido un juego en otros tiempos, en tiempos de equilibrio. Hoy es un grave deber. Su objetivo no es el de entretener la mente con cuentos de hadas y hacer que olvide, sino el de proclamar un estado de movilización a todas las fuerzas luminosas que aún sobreviven en nuestra época de transición y de instar a los hombres a que hagan el máximo para rebasar el animal. (...) Cuanto más escribía, más sentía que al escribir yo luchaba, no por la belleza, sino por la redención. Al contrario de un escritor de verdad, yo no conseguía sacar ningún placer en crear una frase adornada o de combinar una rima sonora; yo era un hombre que luchaba y que estaba herido, un hombre que buscaba la redención. Quería ser libre de mi propia oscuridad interior y de transformarla en luz, quería ser libre de los terribles ancestros que rugían en mí y transformarlos en seres humanos. Y por esto, yo invocaba a los grandes personajes que habían pasado, sucesivamente, por las pruebas más elevadas y las más difíciles... (KAZANTZAKIS, s/d, p.314).

Continuamente, el autor se refiere en su producción a la crisis del momento histórico y a la necesidad de implicamiento para la redención colectiva, lo que confirma la hipótesis de Bien, desautorizando las lecturas que identifican en el autor la alienación y desinterés por las cuestiones éticas. La preocupación por la colectividad es obstinada al punto de figurar en la centralidad de su concepción filosófica, como expresó en la obra de 1927 Ascese:

Somos todos uno, somos todos una esencia en peligro. Un alma que declina del otro lado del mundo arrastra hacia la ruina también a nuestra alma. Un cerebro que se envilece del otro lado del mundo llena nuestras sienes de tinieblas. Porque alguien lucha en los confines del cielo y de la tierra: el Uno. Y si se pierde, la responsabilidad será nuestra. Si se pierde, nosotros nos perderemos también. Porque la salvación del Universo es también nuestra propia salvación. Pero a su vez, la solidaridad entre los hombres no es un lujo de corazones tiernos, sino una profunda necesidad de autoconservación. Una necesidad como, en un ejército en combate, la salvación del compañero de fila (KAZANTZAKIS, 1997, p.130-131). 
La utilización de un vocabulario bélico indica la inserción de Kazantzakis en su tiempo, consciente de que la "época histórica es un momento de crisis violenta [pues] un mundo colapsa y el otro aún no nació. (...) no es una época de equilibrio, en que la cortesía, la concordia, la paz y el amor puedan ser virtudes fecundas". (KAZANTZAKIS, 1997, p.129). Pero, más que una necesidad de hermanamiento para el enfrentamiento de la crisis, la interdependencia es inherente a la propia naturaleza, concepción que Kazantzakis incorpora del Budismo y justamente de la evolución creadora de Bergson. Hombres de todas las razas, animales, vegetales y toda la Tierra hacen parte del mismo círculo de ascensión, los más rudimentarios sirviendo de base para la elevación de las especies más sofisticadas, como elementos inmortales, eternamente permanentes en la vida que no $\operatorname{cesa}^{13}$. No sería, por tanto, difícil establecer la conexión con el lector, convocado al círculo de acción para la redención colectiva por medio de la interlocución imperativa y del uso de la segunda persona del plural, permanentemente presentes y actuantes en Ascese.

Esa obra se constituye en un texto híbrido, situado en lo literario, lo filosófico y lo religioso, en el cual el héroe/lector es incitado a realizar su ascesis en dirección a la afirmación dionisíaca de la vida, lo que consigue realizar por medio de la superación del antagonismo entre las diferentes instancias de lo humano y de la existencia. Ascese se propone como texto transformador y de transformación en la medida en que clama a la acción, no solamente una acción práctica, sino la praxis libertadora de una escritura que crea condiciones de diálogo entre los acontecimientos históricos y la fuerza que los generó y generará permanentemente. Ascese ha sido valorada como el esqueleto y el corazón de toda la obra de Kazantzakis, así como la trayectoria abstracta que será concretizada por Odiseo en el texto épico. Como "transposición poética de la Odisea" (IZZET, 1959, p.7) y osamenta de la producción kazantzakiana, Ascèse condensa, por tanto, el sistema filosófico de Kazantzakis que servirá de base para la composición de las obras posteriores.

La exhortación al lector para el combate conjunto, sea ella sustanciada por el proyecto ético de Kazantzakis o por la apuntada filosofía, instaura la

13 “Tus muertos no yacen sobre la tierra. Se volverán aves, árboles, vientos. Tú te sientas a la sombra de ellos, te nutres de su carne, respiras el hálito de ellos. Se fijan ideas y pasiones que determinan a tu voluntad y tus acciones. Las futuras generaciones no se agitan en un tiempo incierto, distante de ti. Viven, actúan y desean en tus entrañas y en tu corazón". (KAZANTZAKIS, 1997, p. 70-71). 
interlocución que puede ser valorada como la relación del discípulo y maestro, por el tono imperativo característico de Ascèse y por la naturaleza de su contenido, muy próximo a los manuales de ejercicios espirituales, a los versículos bíblicos o igualmente al Bhagavad Gitá. Aunque Ascèse no se constituya en un manual, pues va deconstruyendo en su trayectoria la idea de maestros que señalicen caminos, conduciendo al lector a sus propias valoraciones y a la autonomía de elecciones, la proximidad declarada con el lector probablemente tendrá estimulada la identificación del autor con la elocución de maestro exhortador en el argumento de Ascèse.

La literatura entendida como deber y redención, por el movimiento doble de superación individual y exhortación de la práctica del lector, se vuelve comprometida con la acción y con el momento histórico, uniéndose, de esa forma, a la intencionalidad del autor y a su subjetividad. El autor se vuelve inseparable de su texto, por hacer de él un instrumento de acción y de autotransformación. Es probable, por tanto, que la relación establecida por Kazantzakis con su texto haya llevado a la crítica a volverse continuamente hacia la trayectoria personal del autor, no como un modo de "mejor" valorar su obra, sino ciertamente por un impulso de admiración y encantamiento por la aura que el vuelca, como insectos atraídos a la luz.

Así, se vuelve más provechoso comprender el proyecto literario del autor en el objetivo no de exaltar las peculiaridades de Kazantzakis o de validar sus intenciones, sino de entender cómo vistazos no previstos del proyecto y de la trayectoria personal se presentan en la obra, más allá de lo que el autor suponga haber realizado, favoreciendo así una lectura que establezca la relación -no siempre armónica- entre los elementos canónicos del texto y las tensiones instauradas por su significación ${ }^{14}$.

14 Traducción por Alfredo Fredericksen Neira. Mail de contacto: alfredericksen@ gmail.com Quisiera dedicar con ilusión este trabajo de traducción a la poetisa Carolina Dônega, autora y cálida amiga, que en sus escritos preludia las más bellas auroras. Que la escritura y traducción de los impares explote en el silencio, como la bomba del aforismo final de la Ascética: "That even this one does not exist" (Kazantzakis 1960: 131). Que los que aman y luchan por ello, encuentren su lugar. 


\section{REFERENCIAS BIBLIOGRÁFICAS}

BAUDIER-BIDAL, M.L. (1974) Nikos Kazantzakis. Cómo el hombre se hace inmortal. Buenos Aires: Ediciones Carlos Lohlé.

BIEN, P. (2007) Kazantzakis. Politics of the Spirit. Volume 1. New Jersey: Princeton University Press.

FOUCAULT, M. (1992) O que é um autor? Lisboa: Editora Vega.

IZZET, A. (1959) "Introduction" In: KAZANTZAKIS, N (org.). Ascèse Salvatores Dei. Paris: Librairie Plon.

KAZANTZAKIS N. (1997) Ascese Os Salvadores de Deus. Tradução José Paulo Paes. São Paulo: Ática.

KAZANTZAKIS, N. Testamento para El Greco. Tradução Clarice Lispector. Rio de Janeiro: Artenova, s/d.

KAZANTZAKI, H. (1974) Kazantzakis. El disidente. Visto a través de sus cartas, sus notas, sus textos inéditos. Barcelona: Editorial Planeta.

MACHADO, R. (2006) O Nascimento do Trágico. De Schiller a Nietzsche. Rio de Janeiro: Jorge Zahar Editor.

NUNES, B. (1993) “A Visão Romântica”. En: GUINSBURG, J (org.). $O$ Romantismo. São Paulo: Perspectiva.

QUIROZ PIZARRO, R. (2003) Nikos Kazantzakis. Dimensiones de un poetapensador. Santiago: Universidad de Chile ${ }^{15}$.

15 N. del T.: El presente texto fue publicado por Revista Escrita. Rua Marquês de São Vicente, 225 Gávea/RJ CEP 22453-900 Brasil. Año 2010. Número 11. ISSN 16796888. Mail de contacto: escrita@puc-rio.br. El texto original no incluía abstract en inglés, sino en portugués. Nos hemos permitido añadirlo y perfeccionar el texto en castellano. 